Bioética

\section{QUANDO A CRIANÇA NÃO DEVE SER REANIMADA APÓS PARADA CARDIORRESPIRATÓRIA?}

Embora esta questão seja cada vez mais freqüente, a resposta não é simples, pois envolve a condição clínica da criança, a opinião de médicos especialistas e intensivistas, a opinião da criança e seus responsáveis e aspectos sócio-culturais.

Mesmo em centros tecnologicamente avançados, na maioria dos casos a discussão sobre retirada de tratamento ocorre apenas após tempo prolongado de internação na UTI. Além disso, quando esta decisão é tomada, a maioria dos tratamentos é suspensa abrupta e simultaneamente, e a maioria das crianças morre poucos minutos após a suspensão do tratamento'.

A decisão de retirada de tratamento e de não reanimação deve ser bem fundamentada, discutida amplamente e tomada com antecipação, anterior à deterioração clínica da criança.

Para instituir-se a ordem de não reanimação, a Comissão de Ética do Instituto da Criança (HC FMUSP) propõe as seguintes diretrizes: ${ }^{2}$

\section{Avaliação clínica (a quem dirigir esta decisão)}

a. Paciente terminal - portador de doença crônica em estágio clínico que não permite o resgate de uma situação anterior, com grande comprometimento de suas funções cognitivas e de relação e que determinam, para a equipe que os cuida e para sua família, dúvida quanto ao que seja manter a vida ou prolongar a agonia

b. Pacientes com doença crônica e comprometimento neurológico irreversível que impeça algum contato com o meio e o mantenha em total dependência, em estado vegetativo

\section{Reunião multiprofissional}

Devem participar as equipes envolvidas: especialistas de origem, áreas de emergência, enfermagem. Objetivo: há consenso quanto ao diagnóstico, prognóstico e decisão de não reanimar?

\section{Consulta facultativa à Comissão de Ética \\ 4. Entrevista com o paciente (quando possível) e família}

Transmissão das informações acerca da situação clínica, possibilidades de evolução, recursos disponíveis no sentido de redirecionar o tratamento de curativo para paliativo e possibilidade de decidir-se a não reanimação frente a uma parada cardiorrespiratória. Importante: ouvir e tentar entender como paciente e família se posicionam frente às informações e possibilidades de decisões, identificando seus desejos.

\section{Registro da ordem de não reanimar}

Deve ser registrada claramente, descrevendo todas as decisões acordadas e os procedimentos que devem ou não ser instituídos em caso de parada cardiorrespiratória. Este documento, assinado pelos profissionais envolvidos, além do paciente ou seus responsáveis, deverá ficar na capa do prontuário, e acompanhar o paciente em todos os setores, mesmo após a alta da UTI. As informações da ordem de não reanimar devem ser reavaliadas diariamente e podem ser alteradas, dependendo da opinião da equipe e dos responsáveis.

Cláudio flauzino de Oliveira Eduardo Juan Troster

Referências

I.Zawistowski CA, DeVita MA. A descriptive study of children dying in the pediatric intensive care unit after withdrawal of life-sustaining treatment. Pediatr Crit Care Med 2004; 5:216-23.

\section{Clénica Cirúrgica}

\section{QUANDO INDICAR O TRATAMENTO CONSERVADOR DO TRAUMA ABDOMINAL FECHADO?}

A grande prevalência de traumatismos abdo minais em nosso meio, associado ao grande número de complicações decorrentes de laparotomias não terapêuticas ou negativas, tem colocado em evidência o tratamento conservador nos algorítmos de condutas atuais.

Inicialmente empregado pelos cirurgiões pediátricos, receosos das complicações decorrentes das esplenectomias em crianças, o tratamento conservador no traumatismo abdominal fechado está amplamente difundido nesta faixa etária de pacientes'

A opção por adotar um tratamento não operatório no trauma abdominal fechado exige que sejam obede cidas algumas regras tidas como básicas na abordagem de qualquer paciente traumatizado?

A necessidade de monitorização periódica tanto laboratorial quanto radiológica limita a realização desta conduta a centros com disponibilidade ampla destes recursos.

Dois aspectos são fundamentais na decisão de se adotar o tratamento conservador: ausência de sinais de peritonite ao exame clínico, que exige, para sua avaliação, nível de consciência adequado por parte do paciente; e estabilidade hemodinâmica que, quando ausente, representa indicação absoluta de laparotomia, desde que excluídas outras causas de choque, o que freqüêntemente ocorre em pacientes politraumatizados 3 .

Apesar do enorme avanço tecnológico observado nos últimos anos, incluindo o aprimoramento de exames subsidiários como a ultra-sonografia, a tomografia computadorizada e a radiologia intervencionista, não sendo estes isentos de resultados falso-negativos, o exame físico em momento algum deverá ser esquecido ${ }^{4}$

O principal fator determinante do sucesso deste tipo de conduta é o acompanhamento clínico constante e horizontal do paciente, através de exames físicos meticulosos e seriados, por equipe médica habituada e entrosada no atendimento de politraumatizados.

Osvaldo Antonio Prado Castro Rodrigo VincenzI ELIAS JiRjoss Ilias

Referências

Paulo Kassab

I.Cotte A, Guye E, Diraduryan N, Tardieu D, Varlet F. Management of blunt abdominal trauma in children. Arch Pediatr 2004; I I (4):327-34.
2.Malhotra AK, Latifi R, Fabian TC, Ivatury RR, Dhage S, Bee TK, et al. Multiplicity of solid organ injury: influence on management and outcomes after blunt abdominal trauma. J Trauma 2003; 54(5):925-9.

3.Ozturk H, Dokucu Al, Onen A, Otçu S, Gedik S, Azal OF. Non-operative management of isolated solid organ injuries due to blunt abdominal trauma in children: a fifteen-year experience. Eur J Pediatr Surg 2004: | 4( I):29-34.

4. Sirlin CB, Brown MA, Deutsch R, Andrade-Barreto $A O$, Fortlage DA, Hoyt DB, et al. Screening US for blunt abdominal trauma: objective predictors of falsenegative findings and missed injuries. Radiology 2003 229(3):766-74.

\section{Clínica Médica}

COMO FAZER O DIAGNÓSTICO DA HIPERTENSÃO ARTERIAL

\section{PULMONAR?}

A hipertensão pulmonar é definida como uma síndrome de etiologia diversa, sendo o denominador comum a presença de pressão média de artéria pulmonar (PMAP) superior a $25 \mathrm{mmHg}$ em repouso ou $30 \mathrm{mmHg}$ durante exercício. A nova classificação diagnóstica proposta em Veneza, em 2003, representa um avanço no entendimento fisiopatológico, auxiliando no delineamento da conduta terapêutica. A doença passa a ser classificada em cinco categorias, sendo a primeira a mais estudada sob o ponto de vista etiopatogênico, fisiopatológico, diagnóstico e terapêutico. Alterações genéticas no receptor BMPR II (família TGF-b) são encontradas em 26\% dos casos esporádicos e em $50 \%$ a $60 \%$ dos indivíduos em famílias acometidas.

\section{I.Hipertensão arterial pulmonar}

I.I. Idiopática (esporádica)

I.2. Familial

1.3. Relacionada a:

- Doença vascular por colagenose

- Cardiopatias congênitas

- Hipertensão portal

- Infecção por HIV

- Drogas / toxinas

- Outras

I.4. Hipertensão arterial pulmonar com envolvimento venoso e/ou capilar importante

I.5. Hipertensão pulmonar persistente do recém-nascido 2. Hipertensão pulmonar com doença do coração esquerdo

3.Hipertensão pulmonar associada a desordens do sistema respiratório e/ou hipoxemia

4. Hipertensão secundária à doença trombótica e/ou embólica crônica

5 Miscelânea

Sob o ponto de vista diagnóstico, a seqüência de avaliação apresentada a seguir é imperativa para a adequada caracterização do problema, sua fase evolutiva e condições clínicas associadas. São os seguintes passos:

a) História clínica e exame físico;

b) ECG; RX de tórax ; teste de função pulmonar;

c) Ecocardiografia;

d) Mapeamento ventilação / perfusão; tomografia de alta resolução; pesquisa de trombofilia; 
e) Hemograma e eletroforese de hemoglobina; HIV; função hepática e tireoideana; testes reumatológicos; parasito lógico de fezes e biópsia retal; ultra-sonografia de abdomem; f) Testes funcionais (ergoespirometria e teste de seis minutos de caminhada;

g) Cateterismo cardíaco;

Ainda sob o ponto de vista diagnóstico, interrelações entre achados ecocardiográficos (velocidade de regurgitação tricuspidea - VRT) e dados hemodinâmicos podem ser úteis na diferenciação entre hipertensão arterial pulmonar ausente ou discreta, e doença moderada a avançada. Condutas específicas decorrem da avaliação ecocardiográfica bem conduzida:

\section{VRT $(\mathrm{m} / \mathrm{s})<2,8$ e pressão sistólica da artéria pulmonar (PSAP) provável < 35mmHg: HAP ausente}

\section{VRT (m/s) entre 2,8 e 3,4 e PSAP provável} entre 35 e $50 \mathrm{mmHg}$ :

2.I. sem sintomas - procurar todas as causas predisponentes e agravantes, reavaliar em seis meses a um ano 2.2. com sintomas - cateterismo cardíaco

2.2. I. PSAP $<35$ e PMAP $<25$ - cateterismo com exercício: HAP presente ou ausente

2.2.2. PSAP entre 35 e 50 e PMAP entre 25 e 35 - tratar todas as causas predisponentes e agravantes; acompanhamento clínico; reavaliar em seis meses a um ano

\section{VRT $(\mathrm{m} / \mathrm{s})>3,4$ e PSAP provável $>50 \mathrm{mmHg}$ - HAP sintomática: algoritmo diagnóstico completo e tratamento com vasodilatador}

O cateterismo cardíaco direito deve ser realizado nas condições basal e após estímulo vasodilatador (preferencialmente óxido nítrico, I0ppm, 10 minutos), sendo considerada resposta positiva, a queda na resistência vascular pulmonar superior a $20 \%$ em relação ao valor basal. Alternativamente, tem sido admitido como critério de resposta vasodilatadora positiva, a queda da pressão média arterial pulmonar de no mínimo $10 \mathrm{mmHg}$ em relação ao basal, com valor final inferior a $40 \mathrm{mmHg}$.

Assim, o diagnóstico adequado da hipertensão arterial pulmonar, quanto aos mecanismos fisiopatológicos implicados (vasoconstrição ou vaso-oclusão com envolvimento arterial e/ou venoso) é essencial para a escolha do tratamento adequado. Os dados corretamente obtidos na etapa diagnóstica, serão fundamentais para a verificação da resposta ao tratamento instituído.

Sonia M.Franch

Antônio Augusto Lopes

Referências

I. Diretriz: diagnóstico, avaliação e terapêutica da hipertensão pulmonar. Arq Bras Cardiol 2003: 8I (supl 8).

2. Simonneau G, Galiè N, Rubin LJ, Langleben D, Seeger W, Domenighetti G, et al. Clinical classification of pulmonary hypertension. J Am Coll Cardiol 2004; 43(I2 Suppl I):S5-S I2.

\section{Ginecalogia}

\section{QUANDO É NECESSÁRIO A} COLABORAÇÃO DO CIRURGIÃO PLÁSTICO NOS TRAUMAS VULVARES?

Não raro, os ginecologistas se deparam com traumas genitais das mais variadas causas, como acidentes comjet ski, bicicletas, skate, pós-atividade sexual (sexo oral com vio lência, masturbação com objetos traumáticos e outras práticas agressivas), agressões por animais e queimaduras!.

O raciocínio clínico deve ser complementado com as possibilidades propedêuticas e terapêuticas atuais. A anamnese é fundamental, devendo ser muito bem caracterizado o motivo do trauma, tempo que ocorreu, presença de sangramento, sinais e sintomas de infecção secundária e, se foi feita alguma medicação ou conduta prévia $^{1,2}$. Entretanto, nem sempre se obtém uma informação adequada, pois muitos dos traumas envolvem justificativas sexuais; daí, a necessidade de uma anamnese mais aprofundada. Neste sentido, é fundamental a relação médico-paciente e, o contato com os familiares, uma vez que a caracterização do mecanismo do trauma pode influenciar na investigação diagnóstica de lesões associadas no trato digestivo e urinário ou mesmo a presença de corpos estranhos, não facilmente identificados.

O exame ginecológico é imprescindível e deve conter rigorosa avaliação da uretra; porém, evita-se na fase aguda a sondagem vesical, em face da possibilidade de falso trajeto e de lesões adicionais. Por meio da inspeção externa e do toque retal, a região anal é avaliada na procura de lesões associadas. Deve-se realizar uma minuciosa inspeção da genitália externa e interna, caracterizando o trauma quanto à extensão (acometimento vaginal, clitóris e outros locais); ademais, deve ser investigada a presença ou não de hemorragia e/ou infecção e é evidente que a conduta do ginecologista se baseará nesses achados '.

Entretanto, é prudente que o ginecologista entenda que, em todos os casos de trauma vulvar, é aconselhável ouvir a opinião do cirurgião plástico, pois em algumas situações podem ocorrer perda de tecidos locais com a presença de áreas cruentas que, se não tratadas de maneira adequada, ocasionam comprometimento funcional e estético da região $0^{2,3}$

A abordagem de traumas da região vulvar pode ser realizado na fase aguda, subaguda e crônica. É fato que o tratamento na fase aguda (primeiras 12 horas após o trauma) oferece melhores resultados, com menor índice de complicações, quando comparado à abordagem nas demais fases ${ }^{2,3}$. Nesta fase, o processo inflamatório local exibe menor intensidade e não há infecção, nem os efeitos deletérios da cicatrização por segunda intenção como bridas e sinéquias. $\mathrm{Na}$ fase aguda, os tecidos estão vascularizados e, apesar da colonização bacteriana local, são raras as situações que apresentam infecção invasiva secundária ao trauma. Nesta situação, o cirurgião plástico pode, em conjunto com o ginecologista, promover o debridamento dos tecidos desvitalizados, a limpeza criteriosa da região e proceder a ressutura dos tecidos na forma de retalhos de mucosa genital e/ou pele. Na situação onde há perda de substância, seja da região vaginal ou vulvar, pode-se realizar enxertos de pele autóloga em lâmina de espessura parcial ou total. Entre as principais áreas doadoras merece destaque a prega ínguino-crural e a região dos grandes lábios. Para a realização de enxertos é fundamental que o leito receptor (área cruenta decorrente do trauma) apresente características favoráveis como vascularização, superfície homo gênea, ausência de tecido fibrótico e infecção.
Na fase subaguda, a presença de infecção contra-indica a ressutura dos tecidos locais e a realização de enxertos de pele, uma vez que o risco de deis cência e perda total do enxerto não são desprezíveis. Assim, a melhor conduta é a assepsia rigorosa da região, o uso de compressas frias, a prescrição de antibiótico tópico e sistêmico e o uso de antiinflamatórios. A antibioticoterapia deve ser orientada, de acordo com a flora bacteriana local, indicando a cobertura para cocos gram-positivos (staphilococos, neisseria e streptococos), anaeróbios (peptococos) e espiroquetas (clamídia). Após período de uma a duas semanas e, com o término dos sinais de infecção secundária e edema local, programa-se a recons trução tardia da região. Nesta fase, pode-se realizar a reconstrução, quer com enxertos com maior segurança, quer com a aplicação de retalhos, nos casos de lesões mais profundas ${ }^{2,3}$.

$\mathrm{Na}$ fase crônica, normalmente, não se observam áreas cruentas, uma vez que ocorreu a cicatrização secundária; nestes casos, as principais queixas relacionam-se à dificuldade da higiene da região vaginal e da drenagem fisiológica das secreções, a presença de disúria nas estenoses periuretrais e as limitações na atividade sexua ${ }^{\beta, 4}$. De maneira geral, são quadros mais graves e são observados nas situações onde a paciente não obteve qualquer forma de atendimento na fase aguda e subaguda ou o tratamento foi realizado de maneira inadequada ou por profissionais não habilitados. Na presença de estenose, bridas e sinéquias da região vulvar deve-se programar a reconstrução local em conjunto com o cirurgião plástico. Técnicas de correção de estenose, liberação de bridas e aderências cicatriciais e, mesmo a rotação de retalhos cutâneos locais ou à distância, pode ser aventada com o objetivo de melhorar a função da região ${ }^{2,3}$

Assim, no trauma da região vulvar, é fundamental sua correta identificação e a instituição de uma abordagem cirúrgica imediata dentro de uma assistência multidisciplinar, que obrigatoriamente deve incluir o cirurgião plástico; só desta forma será atingido o sucesso.

José M. Aldrighi Cláudia Maria Santos Aldrigh Alexandre Munhoz

Referências

1. Merritt DF. Vulvar and genital trauma in pediatric and adolescent gynecology. Curr Opin Obstet Gynecol. 2004 Oct; | 6(5):37|-38 I

2. Knapstein P, Friedberg V. Plastic surgery of vulva and vagina. Gynakologe. 198। Mar; | 4(I):42-8.

3. Lees $D H$, Singer $A$. Vaginal surgery for congenital abnormalities and acquired constrictions. Clin Obste Gynecol. 1982 Dec;25(4):883-95.

4. Munarriz R, Talakoub L, Somekh NN, Lehrfeld T, Chudnovsky A, Flaherty E, Goldstein I. Characteristics of female patients with sexual dysfunction who also had a history of blunt perineal trauma. J Sex Marital Ther. 2002;28 Suppl I:175-9

\section{Errata}

Nesta seção, na área de Ginecologia da edição passada, publicada à pág. 239, o título correto do artigo é "Como investigar as anomalias dos ductos Mullerianos?", e não da forma como foi publicado. 